To appear in the International Journal of Mathematical Education

in Science and Technology, Vol. 00, No. 00, Month 20XX, 1-13

\title{
Implementing a flipped classroom approach in a university numerical methods mathematics course
}

\author{
Barbara M. Johnston* \\ School of Natural Sciences and Queensland Micro- and Nanotechnology Center, Griffith \\ University, Queensland, Australia \\ (Received 00 Month 20XX; final version received 00 Month 20XX)
}

\begin{abstract}
This paper describes and analyses the implementation of a 'flipped classroom' approach, in an undergraduate mathematics course on numerical methods. The approach replaced all the lecture content by instructor-made videos and was implemented in the consecutive years 2014 and 2015. The sequential case study presented here begins with an examination of the attitudes of the 2014 cohort to the approach in general as well as analysing their use of the videos. Based on these responses the instructor makes a number of changes (for example, the use of 'cloze' summary notes and the introduction of an extra, optional tutorial class) before repeating the 'flipped classroom' approach the following year. The attitudes to the approach and the video usage of the 2015 cohort are then compared with the 2014 cohort and further changes that could be implemented for the next cohort are suggested.
\end{abstract}

Keywords: flipped classroom; blended learning; instructional videos; university mathematics course; educational technology; mathematics education

\section{Introduction}

In recent years there has been increasing interest in the use of the 'flipped classroom' as an alternative to the traditional lecture-style format in university undergraduate teaching. This interest has been facilitated by technological advances that have made it possible for courses to be presented using a variety of formats (for example, video lectures, including interactive videos, intelligent tutoring systems and interactive classroom activities) [1].

This article focuses on the instructional method known as the 'inverted' [2] or 'flipped' [3] classroom. This can be implemented in a variety of ways, but is, in essence, about students first being exposed to the material prior to class and thus being able to focus on processing that learning in class [4]. In their paper, Bishop and Verlanger [1] argue that the definition should be restricted still further to exclude course designs that do not use videos out of class.

In terms of mathematics, this means that the basic course material (definitions, facts, skills [5]), which involves the lower levels of the revised Bloom's taxonomy [6] of remembering and understanding [7], is introduced outside the classroom via instructional videos. In class, the instructor then takes the role of 'guide on the side' rather than 'sage on the stage' [8] and structures activities that require higher level skills such as applying, analysing and evaluating [7].

According to McGivney-Burelle and Xue [5], the basic tenets that underlie this approach are: (i) highly structured out-of-class time; (ii) evaluation of pre-class preparation

*Corresponding author. Email: Barbara.Johnston@griffith.edu.au 
by the instructor; (iii) class time should involve co-operative problem solving and discussions, as well as (iv) frequent structured practice with feedback from a knowledgeable instructor. Other authors discuss using problem-based learning [9], active learning [10] and peer assisted collaborative learning [11] in class, as well as just-in-time teaching [12] by the instructor. Another aspect that is mentioned [13] is the importance of carefully structuring the face-to-face and online parts of the course to ensure that [4]: (i) students first meet new material before class; (ii) students are given an incentive to do the preparation; (iii) student knowledge is assessed before class and (iv) in-class activities involve higher cognitive processes.

Many previous studies have looked at the effect on students of instructional videos and a summary of these is given in Kay and Kletskin [14]. They conclude that these studies indicate that video podcasts have 'a positive impact on student attitudes, behaviour and learning performance'. A comprehensive list of studies into flipped classrooms in a variety of subject areas is given in Bishop and Verlanger [1], although very few of these involve university mathematics classes. Recently, Bagley [15] has provided suggestions for best practices for implementing a 'flipped' mathematics class and other authors [5, 13, 16-21] have considered 'flipping' aspects of mathematics courses.

These studies suggest that students like aspects of the flipped classroom approach (for example, the more active classroom, student collaboration, closer contact with the instructor), like instructional videos (for example, because of their structure, accessibility, pace) and believe that the videos helped them learn the material. However, the studies are generally less clear about the effect of the method on student learning in university mathematics $[1,15,19,21]$, although a couple of recent studies [16, 20] have found a positive effect on student performance.

Finally, it is worth mentioning some challenges that are also mentioned in relation to flipped classrooms. The first is possible resistance from some students to the new approach [22] and the second is the increase in initial workload for the instructor, not only in terms of producing the videos but also in structuring the course [5, 22].

This study presents a sequential case study that analyses a 'flipped classroom' approach in an undergraduate numerical methods mathematics course in which all the lecture content was replaced by videos. The study considered the following research questions:

(1) what were the instructor's and students' attitudes to the approach;

(2) what use did the students make of the instructional videos that were provided;

(3) based on the answers to (1) and (2), what changes should the instructor make for the next iteration of the course, and

(4) what was the effect of the changes.

The structure of the paper follows that of the research questions. Firstly, it details the way in which the 'flipped classroom' was implemented. It then examines student attitudes to the approach and presents the instructor's reflection on these, as well as an analysis of students' use of the lecture videos. Based on this, the instructor then introduces some changes to the approach and then makes a similar analysis after the course has been run a second time. The paper concludes with reflections about the effect of the changes and some suggestions about possible further changes that could be made for the next iteration of the course.

\section{Methodology}

The 'flipped classroom' approach was introduced in this second year mathematics subject in 2014 when the university began simultaneously offering the course on a second campus. The same situation had occurred in the previous semester in a different mathematics 
course, which was taken by most of these students. Due to budgetary constraints, that course was offered by video conference between the two centres (presented alternately at each campus) and the approach was very unpopular with the students. An awareness of this, in conjunction with a university move towards increased on-line learning, and an interest in the 'flipped classroom' concept based on a workshop run at the university, led the instructor to try a 'flipped classroom' approach in this subject.

\subsection{Implementation of the 'flipped classroom' in 2014}

In 2014, the second year undergraduate subject (Numerical Methods and MATLAB) was presented using a 'flipped classroom' mode, where the lecture time was replaced by instructor-made videos plus a one-hour tutorial class. Prior to 2014, the class consisted of two hours of face-to-face lectures, as well as two hours of computer workshops. The two-hour computer workshops were left unchanged in 2014.

In addition to the videos, students were provided with a book of course notes, which contained a full set of lecture notes, as well as weekly tutorial sheets and computer workshops. Students were expected to read the notes and/or watch the videos, and to attempt the tutorial questions, prior to the classes each week. Full solutions to the tutorial problems were provided after the tutorial class. The tutorial class was used to allow students to receive help and ask questions and to work collaboratively, if they wished to, on the tutorial problems. A short (10 minute) open-book low value quiz (5\% for 10 quizzes) was administered at the end of the tutorial class, mainly to provide an incentive for the students to do the preparation and attend the class.

Students were introduced to the 'flipped classroom' approach via the course profile and an introductory email prior to the first week of class. This set out the way in which the course would be run and suggested that the students watch two introductory videos made by the instructor; one contained more detail about the 'flipped classroom' approach and the other gave an overview of the course content. The approach was also discussed in the first tutorial class. The course content videos did not begin until Week 2, which gave all the students time to get used to and ask any questions they needed to about the approach.

\subsection{The videos}

The videos were produced in the instructor's office using a laptop connected to a WACOM tablet, which had a microphone and small video camera mounted on it, so that the instructor's face was visible in the corner of the screen. The videos were deliberately set up to include the instructor's face in the corner of each of the types of backgrounds used (see Figure 1), in accord with the work of Kizilcec et al. [23], who found that students strongly preferred it.

The laptop was loaded with Screenflow software to record and edit the videos, as well as software (SketchBook Express), which was used to provide a blank document for writing. This set-up meant that the material could be presented via different laptop screens, containing either lecture slides as PDFs that could be written on (see Figure 1(a)), hand-written worked problems (Figure 1(b)) or examples in MATLAB (Figure $1(\mathrm{c})$ ).

The course material was broken down into smaller subsections, resulting in, on average for each week, three videos totalling about 45 minutes. The videos were uploaded into the University's Learning Management System (LMS), from which the students accessed them via a folder containing the videos for that week. An occasional 'optional' video was included for more advanced or interested students. 


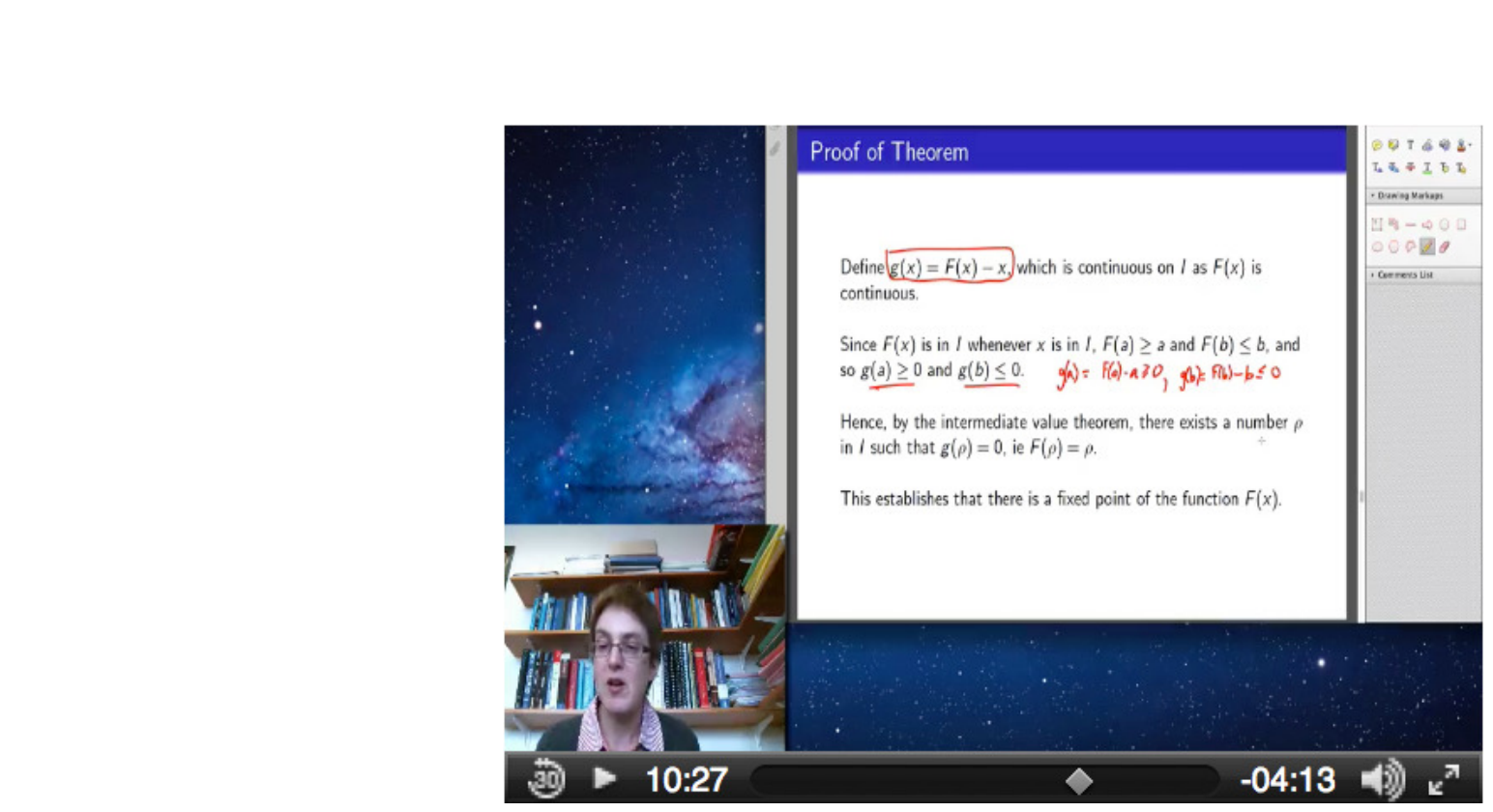

(a)

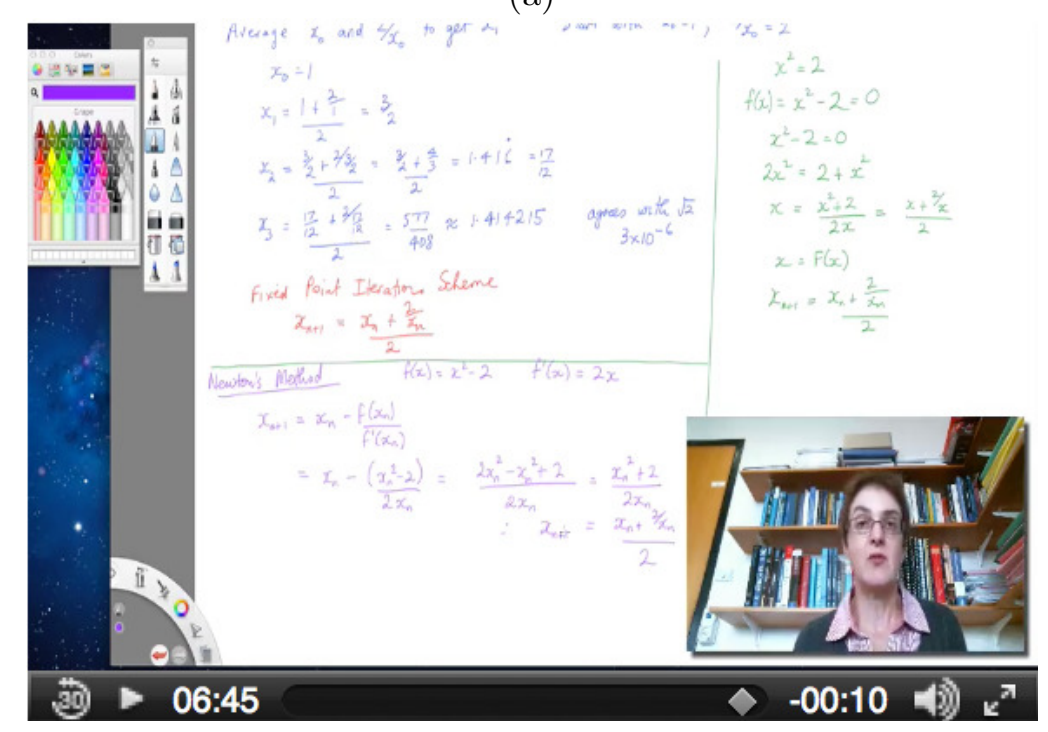

(b)

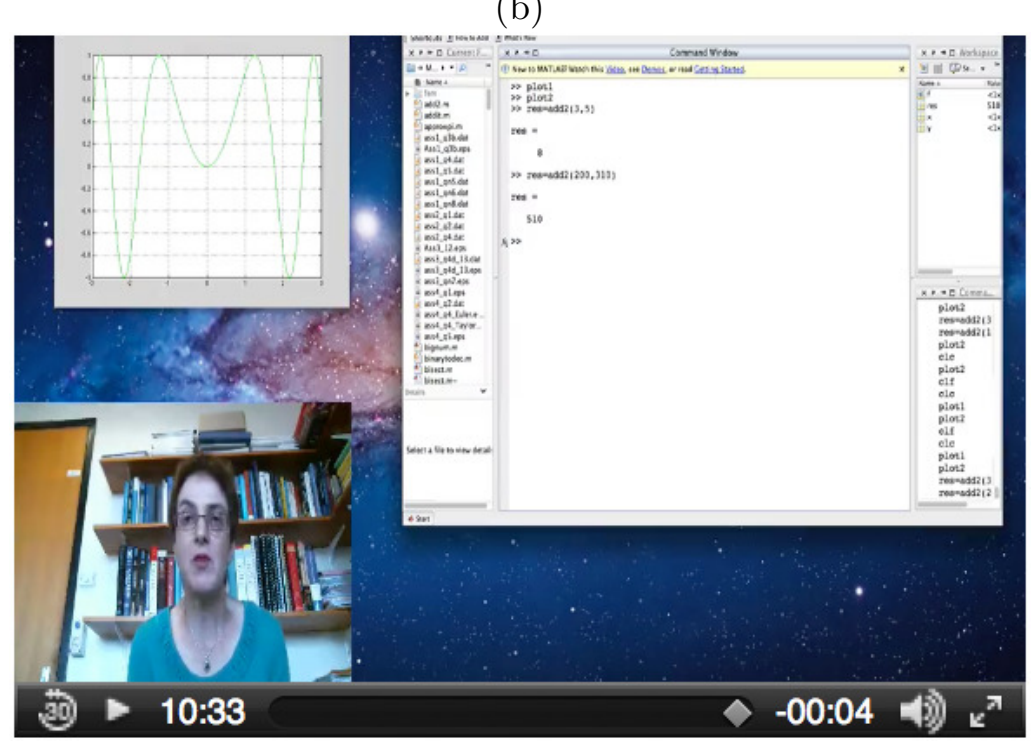

(c)

Figure 1. Images from videos showing the three different screens used.

) 


\subsection{Analytics}

Student responses to the University administered anonymous on-line end-of-semester student survey, Student Experience of Course (SEC), were analysed to probe student attitudes to the 'flipped classroom' approach.

In addition, information about video usage was obtained via reports generated by the LMS, such as the date and number of times an individual student accessed the folder containing the videos for a particular week. Here this will be referred to as 'views', but it does not refer to watching individual videos, since these data were not available. Used carefully, this is an acceptable proxy since the folder does not contain any material other than the videos for that week. Data are presented for Weeks 2-12 of the semester as no new material is covered in Week 13.

\section{Results for the 2014 study}

\subsection{Student Survey Responses (2014)}

In 2014, the cohort comprised classes from two campuses of the University. However, for what follows, the two classes will be combined, giving 38 students in total, $53 \%$ Science students and $47 \%$ Education students.

Cohort responses to the University administered end-of-semester anonymous survey questions are tabulated in Table 1, columns 2-5, for Questions 1-3. Q1 is a standard question that is asked every semester and Q2 and Q3 were chosen from the university additional question databank and were added to the survey. Responses to these questions are on a five point Likert scale ( $1=$ strongly disagree (SD), $2=$ disagree (D), $3=$ neutral $(\mathrm{N}), 4=$ agree $(\mathrm{A}), 5=$ strongly agree $(\mathrm{SA}))$. In Table 1 the category Total Agree includes both A and SA and the Total Disagree includes both D and SD. The response rate for the survey in 2014 was $47 \%$.

The result (4.4) for the course satisfaction question (Table 1, Q1) is comparable to those from the previous two years, when the course used face-to-face lectures; that is, the previous scores were 4.5 (2012) and 4.6 (2013), with the same instructor. The students gave a similar score to these in Q2 in Table 1 about whether the videos assisted them in learning. However, there is a noticeable drop from Q2 to Q3, which refers to whether the blended learning approach was effective for learning, in both the mean and Total Agree results, that is from 4.3 to 3.9 and 16 to 13 (out of 18), respectively, with a commensurate increase in the Neutral response.

In addition to Q1 and other (not presented) fixed questions, students are always given the opportunity to respond to two open-ended questions (Table 1, Q4 and Q5), and comments about videos and the flipped-classroom approach, mentioned here, come from answers to these questions. Student comments that are relevant to this study are summarised in Table 2, with the middle column for Q4 and the right for Q5.

Aspects of the flipped classroom that students found particularly good (Table 2) included: the combination of videos and lecture notes; the quizzes, and the videos (because of flexibility of pace and time of viewing, high quality, and the content being presented in 'small, manageable pieces'). It should be noted that even though only one student disagrees in Q1-3, it is clear that that student feels quite strongly about this method of instruction (Q3 is a SD response unlike Q1 and Q2 which are D responses) with the Q5 comment: 'I honestly found it a bit hard connecting through the online part of the course'. Another student also commented: 'I struggle with not being able to see face to face examples'. Other Q5 responses included the suggestion that an extra tutorial class be held.

In contrast, however, in Q4 many students explicitly commented on how much they 
Table 1. Student responses to University end-of-semester survey.

\begin{tabular}{|c|c|c|c|c|c|c|c|c|}
\hline \multirow[b]{2}{*}{ Question } & \multicolumn{4}{|c|}{$2014(18 / 38=47 \%$ response $)$} & \multicolumn{4}{|c|}{$2015(26 / 43=60 \%$ response $)$} \\
\hline & Mean & $\begin{array}{l}\text { Total } \\
\text { Agree }\end{array}$ & Neutral & $\begin{array}{c}\text { Total } \\
\text { Disagree }\end{array}$ & Mean & $\begin{array}{l}\text { Total } \\
\text { Agree }\end{array}$ & Neutral & $\begin{array}{c}\text { Total } \\
\text { Disagree }\end{array}$ \\
\hline $\begin{array}{l}\text { Q1. Overall I am satisfied with the } \\
\text { quality of this course. }\end{array}$ & 4.4 & 16 & 1 & 1 & 4.5 & 22 & 4 & 0 \\
\hline $\begin{array}{l}\text { Q2. The recorded lectures that I could } \\
\text { download assisted my learning. }\end{array}$ & 4.3 & 16 & 1 & 1 & 4.4 & 23 & 0 & 3 \\
\hline $\begin{array}{l}\text { Q3. The blend of face-to-face and online } \\
\text { learning \& teaching was effective for } \\
\text { my learning in this course. } \\
\text { Q4. What did you find particularly good } \\
\text { about this course? } \\
\text { Q5. How could this course be improved? }\end{array}$ & 3.9 & 13 & 4 & 1 & 4.3 & 20 & 4 & 2 \\
\hline
\end{tabular}

Table 2. Summary of relevant student responses to Questions 4 and 5 from Table 1.

\begin{tabular}{|c|c|c|}
\hline & Q4 Comments & Q5 Comments \\
\hline 2014 & $\begin{array}{l}\text { - Liked videos because: } \\
\text { they can be watched at own pace } \\
\text { they can be watched in own time \& ahead of time } \\
\text { they are shorter length \& in manageable pieces } \\
\text { the quality is good and better than lecture capture } \\
\text { - Liked combination of videos \& notes } \\
\text { - Liked Quizzes, kept them up-to-date }\end{array}$ & $\begin{array}{l}\text { - Did not like videos because: } \\
\text { they don't suit learning style } \\
\text { the student prefers face-to-face } \\
\text { it is hard to connect with the course } \\
\text { - Suggest an extra one-hour tutorial } \\
\text { - Suggest face-to-face solutions of problems }\end{array}$ \\
\hline 2015 & $\begin{array}{l}\text { - Liked mixture of notes, videos and face-to-face } \\
\text { - Liked synergy between the videos and lecture notes } \\
\text { - Videos can be stopped, started, re-watched } \\
\text { - Liked the mixture of slides, MATLAB and problems } \\
\text { - Found the summary (cloze) notes helpful } \\
\text { - Liked the optional class to ask questions }\end{array}$ & $\begin{array}{l}\text { - Approach fails as a teaching method } \\
\text { - Approach is a lazy way of teaching } \\
\text { - You can't ask questions while watching } \\
\text { - Didn't watch many but still did ok }\end{array}$ \\
\hline
\end{tabular}

liked the videos (39\% of respondents) and the approach, with comments such as 'Online videos, rather than lectures, made it easier to take in information' and 'Being a flipped classroom approach, I enjoyed being able to watch and understand the content at my own pace and in my own time.'

\subsection{Viewing Patterns (2014)}

The LMS data shows that the students watched videos on all days of the week, but more often on weekdays. They also watched on almost all hours of the day and night, primarily, however, between $9 \mathrm{am}$ and $9 \mathrm{pm}$, with views peaking in the middle of the day. A histogram from an LMS report for Week 62014 that shows typical viewing (a) days and (b) times is given in Figure 2.

The plot in Figure 3(a) shows the total number of views for Weeks 2-12 for the 2014 (as well as the 2015) cohort. In 2014, there is a marked drop in total views across the semester from 128 views to 28 views. This corresponds (Figure 4(a)) to a drop from $80 \%$ of the class watching in Week 2 to $50 \%$ in Week 12 . If the average number of views for the class is calculated, it is 3.9 for Week 2 dropping to 0.7 in Week 12 (Figure 3(b)), or 4 views per individual student dropping to 1.5 by Week 12 (Figure 4(b)).

The final plot presented in Figure 5(a) breaks down the views into three categories, labelled 'Early', 'Middle' and 'Late'. Here 'Early' refers to watching the weekly videos before or during the week to which they pertain. 'Middle' refers to viewing that occurs after this time, up until the last assignment in the course is due, and 'Late' is after 'Middle'. These plots can be used to infer the purpose for which the students watch the videos by examining the category into which they fall.

The percentages in the categories in Figure 5(a) follow the pattern Early > Middle $>$ Late, with some exceptions around Weeks 9 and 10, indicating that the majority of 


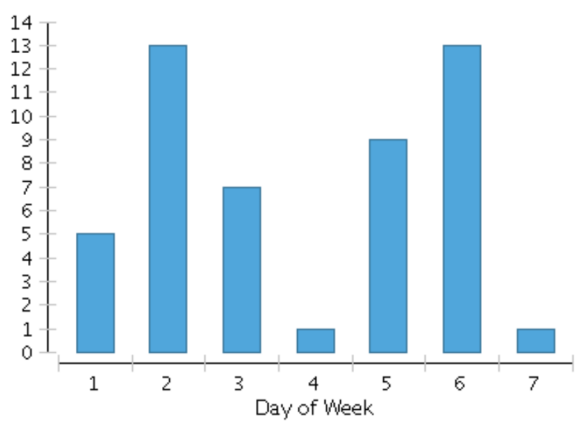

(a)

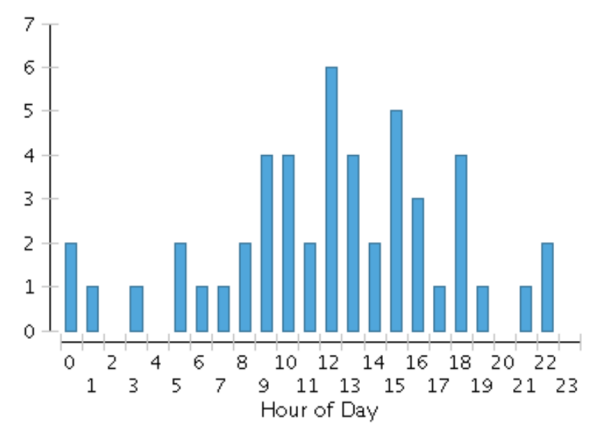

(b)

Figure 2. Histograms from an LMS report showing typical viewing (a) days and (b) times, where 1=Sunday, $2=$ Monday and so on.

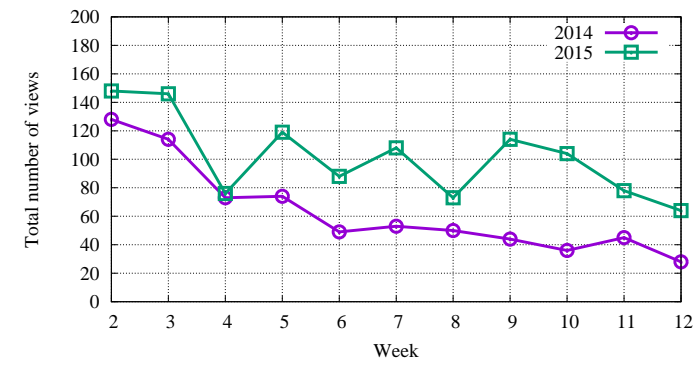

(a)

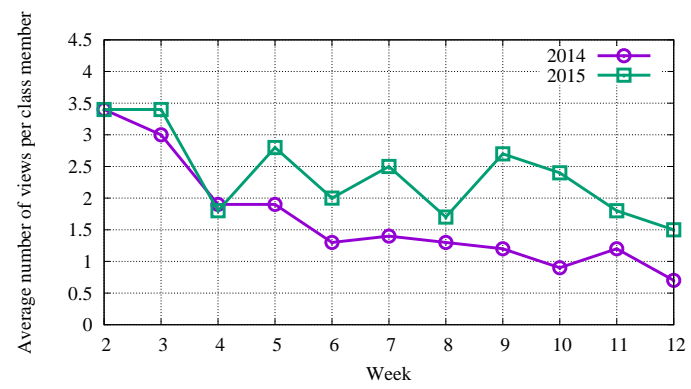

(b)

Figure 3. Views for 2014 and 2015 throughout the semester: (a) total views and (b) average number of views, for the whole cohort.

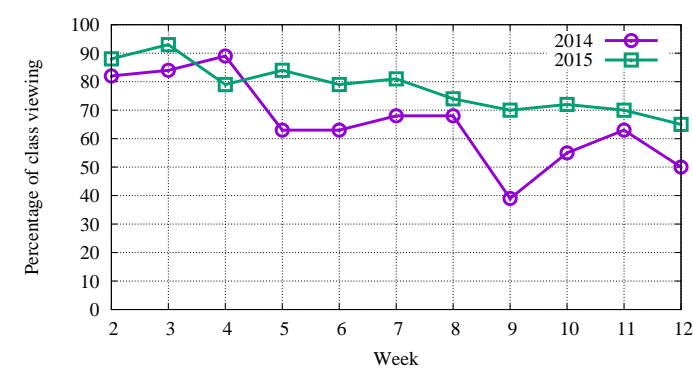

(a)

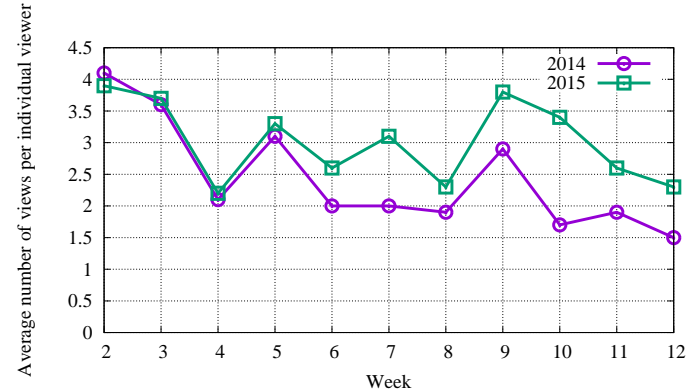

(b)

Figure 4. Views for 2014 and 2015 throughout the semester: (a) percentage of class and (b) average number of views per individual viewer.

video watching occurred before class. Analysis of the 'Middle' category indicates that students probably watch them for two reasons; the first is to catch up if they missed seeing the video at the 'correct' time, and the second is to catch up on material they need to complete an assignment. For example, a spike in Week 9 can be seen in the 'Middle' category in Figure 5(a), along with a drop in the Week 9 'Early' category. This indicates that students did not watch the Week 9 videos in Week 9, probably because the second assignment (which did not require that material) was due then. The students then watched the videos at a later time (Week 11), which in this case corresponded to the third assignment. Similarly, the 'Early' trough and 'Middle' peak in Week 5 can be explained by preparation for the first assignment. 


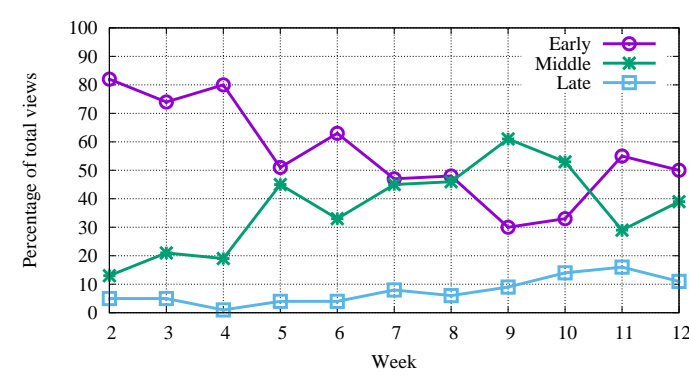

(a)

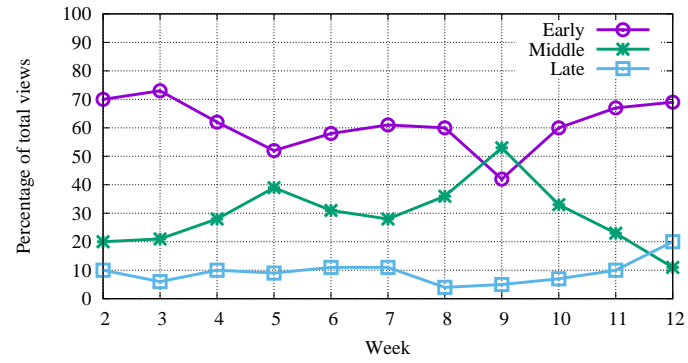

(b)

Figure 5. Views for (a) 2014 and (b) 2015 throughout the semester in the 'Early', 'Middle' and 'Late' time periods (see the text for definitions).

The values in the 'Late' category mostly lie in the range 5-7\% in 2014, except for the last four weeks where they are higher. Given the high percentages of students watching videos, at least in the first half of the semester, it seems reasonable to conclude that a high proportion of the 'Late' category represents students re-watching videos as part of examination preparation. This is confirmed by looking at the viewing of individual students, which shows that quite a number of students watched a particular week's videos in two or three of these time periods.

One final result relates to the number of students who watched very few videos. For example, one student did not view videos for 10 of the 11 weeks, two students did not view for 9 weeks and one did not view for 7 weeks. What is interesting is that most of these students did not fail the course. In addition, there were a couple of quite high performing students who watched videos in only about half the weeks. It is the instructor's opinion that this is possible because of two factors: the first is that there are comprehensive notes available for the students who wish to read and work through the material on their own; and the second is related to the MATLAB workshops, which are crucial in that they reinforce the lecture material.

\section{Instructor reflections on the 2014 study}

It appears from the results given in Table 1 that, while the vast majority of the students have positive attitudes to the videos themselves (Q2) they are less certain about the 'flipped classroom' approach in general (Q3). The instructor suspects that at least part of this may be related to the call (Table 2) for the instructor to work solutions to problems face-to-face, during which students can ask questions. This was in accord with the instructor's view that the tutorial class was too 'passive' and the students needed to be encouraged to more actively engage with the material, rather than simply work on tutorial questions.

So the first change that was implemented for 2015 was to introduce an extra tutorial class. This was to be held before the usual tutorial class and would be optional. This would allow students who had questions about the video material or how to solve the tutorial problems to ask them on an individual basis. Alternatively, the class could be used by students as a time to simply work, individually or collaboratively, on the tutorial problems (and seek help if it was needed). This would then allow the second hour to be spent with the class more actively engaging with the instructor, who would then have time to demonstrate solutions to problems and discuss common misconceptions.

Another concerning statistic was the drop in the percentage of students watching videos, from a high of $90 \%$ to just $50 \%$ at the end of the semester (Figure 3). This 
was more difficult to address, but it was decided to introduce a set of 'cloze' notes for each module in the course. These were included in the course book in 2015 and consisted of sentences, which summarised the material in that module, that contained blank spaces for the students to fill in [24]. It was hypothesized that these might perform a number of functions: to help students concentrate on the videos as they watched them; to help students recognise a missed concept; once completed, to act as a summary for the module; to encourage students to watch more videos/read the notes before class, and, since the instructor filled in the blanks in class using student input, to act as a reinforcement for the new concepts.

So, in 2015, two classes were held per week, in addition to the computer workshops: an optional one-hour class, and a revamped tutorial class, which began with filling in the 'cloze' sheets, which allowed the instructor to emphasize or reiterate important points and clear up common misunderstandings. Next the instructor worked through the solutions to some of the more difficult problems for the class, as requested by the students. Lastly, the same type of short quiz as given in 2014 was administered.

\section{Comparison of 2015 results with 2014}

In 2015, the cohort (46 students) was again comprised of classes from two campuses of the University and made up of approximately half Education and half Science students (in this case $47 \%$ Science and $53 \%$ Education). However, there were potentially some differences between the Science students in the two years, as the 2014 cohort contained eight students studying Advanced or Accelerated versions of the degree, whereas in the 2015 cohort there were only two of these students.

Student attendance at the tutorial class, which could be determined by the number of students who attempted the quiz, was consistently higher in 2015 (80\% on average) than in 2014 (70\% on average). In both years the attendance dropped a little towards the end of semester, but not substantially. Based on the attendance rates and the importance students seemed to place on the quiz, it would seem, somewhat surprisingly, that the short $5 \%$ quiz is sufficient incentive for students to prepare for and attend the class.

\subsection{Student Survey Responses}

The 2015 student responses to the same fixed and open-ended questions from the University administered SEC survey as the 2014 students are given in columns 6-9 of Table 2 . The response rate $(26 / 43=60 \%)$ is higher than in 2014 , when it was $47 \%$, even though the survey was promoted in the same fashion in each year. The responses to Q1 and Q2 of Table 1 are similar, whereas the 2015 response to Q3 of mean 4.3 (20/26=77\% Total Agree) is higher than the 2014 value of $3.9(13 / 18=72 \%)$. It is interesting that in both years there is an increase in the number of Neutral responses from Q2 to Q3.

Extra comments for Q4 and Q5 in 2015 (given below the line in Table 2) have only been included if they are different to those given in 2014, as many of the comments are similar in the two years. As in 2014, the numbers of students in 2015 who disagreed in Q2 or Q3 of Table 1 are small (2-3 students), but once again in one case (there is one $\mathrm{SD}$ in each of Q2 and Q3) they are strongly held.

The numbers of students who watched very few videos are similar in 2014 and 2015. It is interesting that one student comments that they 'didn't watch many, but still did ok' and, based on individual viewing statistics, this is certainly the case for a number of the students.

Once again, however, the great majority of the students liked the approach, repeating 
many of the comments from 2014. For example, they pointed out that they liked the different ways in which they could access the materials (notes, videos and face-to-face) and the different ways that the material was presented within the videos (slides, MATLAB and problems). Students commented that they found the extra class useful and liked the 'cloze' notes, which 'helped me focus on the salient parts of the content' and were 'extremely useful for review' (both positive benefits that were hypothesised in Section 4). The number of explicit positive comments about the videos corresponded to $48 \%$ of the students who answered that question in 2015 and a number of students were very enthusiastic about the videos with comments such as 'Love the online lectures', 'The videos were a HUGE help' and 'I loved the videos!'.

\subsection{Viewing Patterns}

Once again students were found to watch the videos on all days of the week and most hours of the day.

Each of the graphs presented in the previous Section was also produced for the 2015 cohort, that is Figures 3-5. Qualitatively the 2014 and 2015 versions are quite similar; quantitatively, it is generally the case that the values for 2015 are higher than those for 2014. As would be expected for a slightly larger class the total number of views Figure 3(a) is higher in 2015 than 2014, but it is also true for the average number of views per student (Figures 3(b), 4(b)). For example, the average number of views per individual student (Figure 4(b)) after Week 5 are around 0.5-1 higher in 2015 than in 2014. In addition, while both cohorts start with 80-90\% of students watching videos (Figure 4(a)), in 2015 a much larger percentage (65\%) are still watching in week 12, compared with only $50 \%$ in 2014. Also, for the whole semester except for Week 4, a markedly higher percentage (generally greater than 10\%) of 2015 students were watching videos than 2014 students.

\section{Discussion}

Many of the reasons that the students gave for liking or disliking the videos (Table 1) are similar to those found in previous studies in 'flipped' mathematics courses [5, 16] or the use of self-study pre-calculus video podcasts [14]. Also, the study by Kay and Kletskin [14], where video podcasts were used to improve students' pre-calculus knowledge, found that the number of podcasts viewed per day (and the mean time per visit) increased when students were preparing for the diagnostic test. This has parallels with the increase in viewing, found here (Figure 5) in Weeks 5 and 9, when students were completing assignments.

One aspect of the flipped classroom approach that has been highlighted by previous authors $[1,4,5,21]$ as integral to its success is the use of the face-to-face class time for activities that promote deeper learning, such as peer assisted collaborative learning and solving problems with instructor support. This is probably why the tutorials appeared to the instructor to work much better in 2015. In that case the extra optional tutorial class could be used for the above, which then allowed the instructor to use the second tutorial class to summarise the material using the 'cloze' sheets, to clear up common errors and to demonstrate solutions to problems.

However, it was found that the timing of the extra class was also extremely important in terms of student attendance. This is illustrated by the behaviour of the two classes that made up the 2015 cohort. For one class, the tutorial and extra tutorial were on different days and very few students attended the optional class. In the other case, the two classes were consecutive and about two-thirds of the class attended both for the 
entire semester.

It is not clear why, in both 2014 and 2015, three students who agreed with Q2 of Table 1 (videos assisted learning) gave a neutral response to Q3 (blended learning is effective for learning) and one student who disagreed with Q2 in 2015 gave a neutral response to Q3. Such small numbers may not actually be significant or they be related to the phrasing of the question (and this is something that could be investigated in the future).

Despite the final subject results of the 2014 and 2015 cohorts being very similar $(72.4 \%$ (2014) and $73.2 \%(2015)$ ), it appears that there is possibly a difference in the engagement of each cohort with the course. This is certainly true of student engagement with the videos $(65 \%$ watching at the end of the semester in 2015 compared with $50 \%$ in 2014 and at least $10 \%$ higher for the whole of 2015)), and is reflected in the average tutorial attendance (80\% in 2015 compared with $70 \%$ in 2014). Also a higher percentage of 2015 students chose to complete the end-of-semester survey (60\% compared with $47 \%$ ). Regardless of whether the 2015 students were more engaged in the subject because of the innovations that were introduced that year: that is, the 'cloze' summary notes and the extra optional one hour tutorial class, it is apparent (based on student comments) that it is worthwhile to continue with these modifications, and to ensure, if possible, that the optional class is held directly before the tutorial class.

Another possible modification would be to still run two consecutive hours of classes, but remove the optional aspect of the first hour. That would allow that first hour to be used more productively, with more 'active' learning activities that would help the students to engage more fully with the material. However, it should be noted that this is increasing the amount of class time by stealth, as it would mean that students would then have four hours of class time (as they did prior to 2014) plus nearly another hour watching videos.

Ideally, some additional modification to the 'flipped classroom' approach would be made that would ensure that the number of students watching videos did not drop so much across the semester (although in fairness, when the class was run with face-to-face lectures in the past, the attendance rates for students were not generally higher than the percentages of students who watched the videos in 2015). One suggestion would be to introduce some type of on-line assessment of a student's knowledge of the week's videos prior to class. This has the merit of the instructor being aware of and therefore able to deal with common misconceptions in class, in addition to encouraging interaction with the material before class.

\section{Conclusions}

In terms of student attitudes to the 'flipped classroom' approach and their video usage, it has been demonstrated that, while a very small number of students did not like the videos, the vast majority did, with some students commenting very enthusiastically about them. Student comments about what they liked about the videos and the course centered around convenience and flexibility of time and place of viewing, as well as flexibility of pace of learning and enjoying the mixture of learning modes. Negative comments related to preferring 'face-to-face' learning and lack of engagement.

It is worth noting that, despite the positive response of many students to the videos and to aspects of the 'flipped classroom', the course satisfaction scores were similar to (but not higher than) previous years when the course was taught using conventional lectures. Also, the fact that the course results for the two cohorts were similar $(72.4 \%$ in 2014 and $73.2 \%$ in 2015) does not indicate whether student learning was increased using this approach, due to differences in the cohorts. Regardless of the above, the instructor believes that the 'flipping' the classroom for this course was a worthwhile exercise, mainly because of the 
fact that the approach caters to different student learning styles and because it means that class-time can be used more productively.

\section{Acknowledgment}

The author would like to thank Wendy Loughlin for helpful discussions about this manuscript.

\section{References}

[1] Bishop JL, Verleger MA. The flipped classroom: A survey of the research. In: Proceedings of the 120th ASEE Annual Conference and Exposition. American Society for Engineering Education; 2013. p. Paper ID 6219.

[2] Lage MJ, Platt GJ, Treglia M. Inverting the classroom: A gateway to creating an inclusive learning environment. J Econ Instruct. 2000;31(1):30-43.

[3] Baker JW. The 'classroom flip': Using web course managment tools to become the guide by the side. In: Selected papers from the 11th International Conference on College Teaching and Learning; 2000. p. 9-17.

[4] Brame CJ . 2013 [cited 12/09/2015]; Available from: https://cft.vanderbilt.edu/guides-subpages/flipping-the-classroom.

[5] McGivney-Burelle J, Xue F. Flipping calculus. Primus. 2013;23(5):477-486.

[6] Krathwohl DR. A revision of Bloom's taxonomy: An overview. Theory Prac. 2002;41(4):212218.

[7] Sarawagi N. Flipping an introductory programming course - Yes you can! J Comput Sci Coll. 2013;28(6):186-188.

[8] King A. From sage on the stage to guide on the side. College Teach. 1993;41(1):30-35.

[9] Hmelo-Silver CE. Problem-based learning: What and how do students learn? Educ Psychol Rev. 2004;16(3):235-266.

[10] Prince M. Does active learning work? a review of the research. J Eng Educ. 2004;93:223-232.

[11] Topping K, Ehly S, editors. Peer-Assisted Learning. New York and London: Routledge; 1998.

[12] Novak G, Gavrin A, Christian W, et al. Just-in-time teaching: blending active learning with web technology. Upper Saddle River (NJ): Addison-Wesley; 1999.

[13] Strayer JF. How learning in an inverted classroom influences cooperation, innovation and task orientation. Learn Environ Res. 2012;15:171-193.

[14] Kay R, Kletskin I. Evaluating the use of problem-based video podcasts to teach mathematics in higher education. Comput Educ. 2012;59:619-627.

[15] Bagley S. Improving student success in calculus : A comparison of four college calculus classes [dissertation]. San Diego State University; 2014.

[16] Love B, Hodge A, Grandgenett N, et al. Student learning and preceptions in a flipped linear algebra course. Int J Math Educ Sci Tech. 2014;45(3):317-324.

[17] Dove A. Students' perceptions of learning in a flipped statistics class. In: McBride R, Searson M, editors. Proceedings of Society for Information Technology and Teacher Education International Conference; Association for the Advancement of Computing in Education; Chesapeake (VA); 2013. p. 393-398.

[18] Syam MI. Possibility of applying flipping classroom method in mathematics classes in foundation program at Qatar university. In: Proceedings of SOCIOINT14 - International Conference on Social Science and Humanities; September; 2014. p. 180-187.

[19] Loch B, Borland R. The transition from traditional face-to-face teaching to blended learning - implications and challenges from a mathematics discipline perspective. In: Hegarty B, McDonald J, Loke SK, editors. Rhetoric and Reality: Critical perspectives on educational technology; Proceedings Ascilite Dunedin 2014; 2014. p. 708-712.

[20] Loch B, Jordan CR, Lowe TW, et al. Do screencasts help to revise prerequsite mathematics? 

then

\begin{abstract}
An investigation of student performance and perception. Int J Math Educ Sci Tech Educ. 2014;45(2):256-268.

[21] Jungic V, Kaur H, Mulholland J, et al. On flipping the classroom in a large first year calculus course. Int J Math Educ. 2015;46(4):1-8.

[22] Stone BB. Flip your classroom to increase active learning and student engagement. In:
Proceedings of 28th annual conference on Distance Teaching and Learning; Madison (WI);

[22] Stone BB. Flip your classroom to increase active learning and student engagement. In:
Proceedings of 28th annual conference on Distance Teaching and Learning; Madison (WI); 2012. p. 1-5.

[23] Kizilcec RF, Papadopoulos K, Sritanyaratana L. Showing face in video instruction: Effects on information retention, visual attention, and affect. In: Proceedings of the SIGHI Conference
on Human Factors in Computer Systems; Association for Computing Machinery; New York; information retention, visual attention, and affect. In: Proceedings of the SIGHI Conference
on Human Factors in Computer Systems; Association for Computing Machinery; New York; 2014. p. 2095-2102. [24] Marr B, Morgan B. Enhancing teaching: integrating language, literacy and
numeracy into VET programs. 2005 [cited 23 June 2016]; Available from: Marr B, Morgan B. Enhancing teaching: integrating language, literacy and
numeracy into VET programs. 2005 [cited 23 June 2016]; Available from: http://mams.rmit.edu.au/5aboeknw8tdv.pdf. he://mams.rmit.edu.au/5aboeknw8tdv.pdf.

西

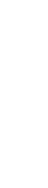

